\title{
Coupled coincidence point theorems for $\alpha-\psi$-contractive type mappings in partially ordered metric spaces
}

\author{
Preeti Kaushik', Sanjay Kumar ${ }^{1}$ and Poom Kumam²*
}

\section{"Correspondence:}

poom.kum@kmutt.ac.th

${ }^{2}$ Department of Mathematics,

Faculty of Science, King Mongkut's

University of Technology, Thonburi

(KMUTT), Bang Mod, Thrung Khru,

Bangkok, 10140, Thailand

Full list of author information is

available at the end of the article

\begin{abstract}
In this paper, we introduce the notion of $\alpha$ - $\psi$-contractions and $(\alpha)$-admissibility for a pair of mappings. In fact, our theorem is a generalization of the result of Mursaleen et al. (Fixed Point Theory Appl. 2012, doi:10.1186/1687-1812-2012-228). At the end, we shall provide an example in support of our main result.
\end{abstract}

MSC: $47 \mathrm{H} 10 ; 54 \mathrm{H} 25 ; 34 \mathrm{~B} 15$

Keywords: coupled coincidence point; $\alpha$ - $\psi$-contractive mapping; partially ordered metric space

\section{Introduction}

Fixed point problems of contractive mappings in metric spaces endowed with a partial order have been studied in a number of works. Bhaskar and Lakshmikantham [1] established coupled fixed point results for mixed monotone operators in partially ordered metric spaces. Afterwards, Lakshmikantham and Ćirić [2] proved coupled coincidence and coupled common fixed point theorems for nonlinear contractive mappings in partially ordered complete metric spaces. Choudhury and Kundu [3], Ćirić et al. [2], Luong and Thuan [4], Nieto and López [5, 6], Ran and Reurings [7] and Samet [8] presented some new results for contractions in partially ordered metric spaces. Ilić and Rakočević [9] determined some common fixed point theorems by considering the maps on cone metric spaces. For more details on fixed point theory and related concepts, we refer to [4, 8-18] and the references therein.

Most recently, Samet et al. [12,15] defined an $\alpha-\psi$-contractive and $\alpha$-admissible mapping and proved fixed point theorems for such mappings in complete metric spaces.

The aim of this paper is to determine some coupled coincidence point theorems for generalized contractive mappings in the framework of partially ordered metric spaces.

\section{Preliminaries}

Before proceeding to our main result, we give some preliminaries.

Definition 2.1 [1] Let $(X, \leq)$ be a partially ordered set, and let $F: X \times X \rightarrow X$ be a mapping. Then $F$ is said to have the mixed monotone property if $F(x, y)$ is monotone non-

\section{空 Springer}

C2013 Kaushik et al.; licensee Springer. This is an Open Access article distributed under the terms of the Creative Commons Attribution License (http://creativecommons.org/licenses/by/2.0), which permits unrestricted use, distribution, and reproduction in any medium, provided the original work is properly cited. 
decreasing in $x$ and is monotone non-increasing in $y$; that is, for any $x, y \in X$,

$$
\begin{array}{llll}
x_{1}, x_{2} \in X, & x_{1} \leq x_{2} \quad \text { implies } & F\left(x_{1}, y\right) \leq F\left(x_{2}, y\right) \quad \text { and } \\
y_{1}, y_{2} \in X, \quad y_{1} \leq y_{2} \quad \text { implies } & F\left(x, y_{1}\right) \geq F\left(x, y_{2}\right) .
\end{array}
$$

Definition 2.2 [1] An element $(x, y) \in X \times X$ is said to be a coupled fixed point of the mapping $F: X \times X \rightarrow X$ if

$$
F(x, y)=x \quad \text { and } \quad F(y, x)=y .
$$

Definition 2.3 [2] Let $(X, d)$ be a partially ordered set, and let $F: X \times X \rightarrow X$ and $g$ : $X \rightarrow X$ be two mappings. We say $F$ has the mixed $g$-monotone property if $F$ is monotone $g$-non-decreasing in its first argument and is monotone $g$-non-increasing in its second argument, that is, for any $x, y \in X$

$$
\begin{array}{llll}
x_{1}, x_{2} \in X, & g\left(x_{1}\right) \leq g\left(x_{2}\right) \quad \text { implies } & F\left(x_{1}, y\right) \leq F\left(x_{2}, y\right) \quad \text { and } \\
y_{1}, y_{2} \in X, & g\left(y_{1}\right) \leq g\left(y_{2}\right) \quad \text { implies } & F\left(x, y_{1}\right) \geq F\left(x, y_{2}\right) .
\end{array}
$$

Definition 2.4 [2] An element $(x, y) \in X \times X$ is called a coupled coincidence point of mappings $F: X \times X \rightarrow X$ and $g: X \rightarrow X$ if

$$
F(x, y)=g(x) \quad \text { and } \quad F(y, x)=g(y) .
$$

Definition 2.5 [2] Let $X$ be a non-empty set and $F: X \times X \rightarrow X$ and $g: X \rightarrow X$. We say $F$ and $g$ are commutative if $g(F(x, y))=F(g(x), g(y))$.

Definition 2.6 [19] Denote by $\Psi$ the family of non-decreasing functions $\psi:[0,+\infty) \rightarrow$ $[0,+\infty)$ such that $\sum_{n=0}^{\infty} \psi n(t)<t$ for all $t>0$, where $\psi_{n}$ is the $n$th iterate of $\psi$ satisfying

(i) $\psi^{-1}(\{0\})=\{0\}$,

(ii) $\psi(t)<t$ for all $t>0$, and

(iii) $\lim _{r \rightarrow t+} \psi(r)<t$ for all $t>0$.

Lemma 2.7 [19] If $\psi:[0, \infty] \rightarrow[0, \infty]$ is non-decreasing and right continuous, then $\psi_{n}(t) \rightarrow 0$ as $n \rightarrow \infty$ for all $t \geq 0$ if and only if $\psi(t)<t$ for all $t>0$.

Definition 2.8 [19] Let $(X, d)$ be a partially ordered metric space and $F: X \times X \rightarrow X$, then $F$ is said to be $(\alpha, \psi)$-contractive if there exist two functions $\alpha: X^{2} \times X^{2} \rightarrow[0,+\infty)$ and $\psi \in \Psi$ such that

$$
\begin{gathered}
\alpha((x, y),(u, v)) d(F(x, y), F(u, v)) \leq \psi\left(\frac{d(x, u)+d(y, v)}{2}\right), \\
x, y, u, v \in X \text { with } x \geq u \text { and } y \leq v .
\end{gathered}
$$


Definition 2.9 [19] Let $F: X \times X \rightarrow X$ and $\alpha: X^{2} \times X^{2} \rightarrow[0,+\infty)$ be two mappings. Then $F$ is said to be $(\alpha)$-admissible if

$$
\begin{aligned}
& \alpha((x, y),(u, v)) \geq 1 \quad \text { implies } \quad \alpha((F(x, y), F(y, x)),(F(u, v), F(v, u))) \geq 1 \\
& \quad \text { for all } x, y, u, v \in X .
\end{aligned}
$$

Now, we will introduce our notions.

Definition 2.10 Let $(X, d)$ be a partially ordered metric space, and let $F: X \times X \rightarrow X$ and $g: X \rightarrow X$ be two mappings. Then the maps $F$ and $g$ are said to be $(\alpha, \psi)$-contractive if there exist two functions $\alpha: X^{2} \times X^{2} \rightarrow[0,+\infty)$ and $\psi \in \Psi$ such that

$$
\alpha((g(x), g(y)),(g(u), g(v))) d(F(x, y), F(u, v)) \leq \psi\left(\frac{d(g(x), g(u))+d(g(y), g(v))}{2}\right)
$$

for $x, y, u, v \in X$ with $g(x) \geq g(u)$ and $g(y) \leq g(v)$.

Definition 2.11 Let $F: X \times X \rightarrow X, g: X \rightarrow X$ and $\alpha: X^{2} \times X^{2} \rightarrow[0,+\infty)$ be mappings.

Then $F$ and $g$ are said to be $(\alpha)$-admissible if

$$
\begin{aligned}
& \alpha((g(x), g(y)),(g(u), g(v))) \geq 1 \quad \text { implies } \quad \alpha((F(x, y), F(y, x)),(F(u, v), F(v, u))) \geq 1 \\
& \quad \text { for all } x, y, u, v \in X .
\end{aligned}
$$

\section{Main results}

Recently, Mursaleen et al. [19] proved the coupled fixed point theorem with $\alpha$ - $\psi$-contractive conditions in a partially ordered metric space as follows.

Theorem 3.1 [19] Let $(X, \leq)$ be a partially ordered set, and let there exist a metric $d$ on $X$ such that $(X, d)$ is a complete metric space. Let $F: X \times X \rightarrow X$ be a mapping, and suppose that $F$ has the mixed monotone property. Suppose that there exist $\psi \in \Psi$ and $\alpha: X^{2} \times X^{2} \rightarrow$ $[0,+\infty)$ such that for $x, y, u, v \in X$, the following holds:

$$
\begin{aligned}
& \alpha((x, y),(u, v)) d(F(x, y), F(u, v)) \leq \psi\left(\frac{d(x, u)+d(y, v)}{2}\right) \\
& \text { for } x, y, u, v \in X \text { with } x \geq u \text { and } y \leq v .
\end{aligned}
$$

\section{Suppose also that}

(i) $F$ is $(\alpha)$-admissible.

(ii) There exist $x_{0}, y_{0} \in X$ such that

$$
\alpha\left(\left(x_{0}, y_{0}\right),\left(F\left(x_{0}, y_{0}\right), F\left(y_{0}, x_{0}\right)\right)\right) \geq 1 \text { and } \alpha\left(\left(y_{0}, x_{0}\right),\left(F\left(y_{0}, x_{0}\right), F\left(x_{0}, y_{0}\right)\right)\right) \geq 1 \text {. }
$$

(iii) $F$ is continuous.

If there exist $x_{0}, y_{0} \in X$ such that $x_{0} \leq F\left(x_{0}, y_{0}\right)$ and $y_{0} \geq F\left(y_{0}, x_{0}\right)$, then $F$ has a coupled fixed point, that is, there exist $x, y \in X$ such that

$$
F(x, y)=x \quad \text { and } \quad F(y, x)=y .
$$


Theorem 3.2 Let $(X, \leq)$ be a partially ordered set, and let there exist a metric $d$ on $X$ such that $(X, d)$ is a complete metric space. Let $F: X \times X \rightarrow X$ and $g: X \rightarrow X$ be maps, and let $F$ have the g-mixed monotone property. Suppose that there exist $\psi \in \Psi$ and $\alpha: X^{2} \times X^{2} \rightarrow$ $[0,+\infty)$ such that for $x, y, u, v \in X$, the following holds:

$$
\begin{aligned}
& \alpha((g(x), g(y)),(g(u), g(v))) d(F(x, y), F(u, v)) \\
& \quad \leq \psi\left(\frac{d(g(x), g(u))+d(g(y), g(v))}{2}\right)
\end{aligned}
$$

for all $x, y, u, v \in X$ with $g(x) \geq g(u)$ and $g(y) \leq g(v)$.

Suppose also that

(i) F and $g$ are $(\alpha)$-admissible.

(ii) There exist $x_{0}, y_{0} \in X$ such that

$$
\begin{aligned}
& \alpha\left(\left(g\left(x_{0}\right), g\left(y_{0}\right)\right),\left(F\left(x_{0}, y_{0}\right), F\left(y_{0}, x_{0}\right)\right)\right) \geq 1 \text { and } \\
& \alpha\left(\left(g\left(y_{0}\right), g\left(x_{0}\right)\right),\left(F\left(y_{0}, x_{0}\right), F\left(x_{0}, y_{0}\right)\right)\right) \geq 1 .
\end{aligned}
$$

(iii) $F(X \times X) \subseteq g(X), g$ is continuous and commutes with $F$.

(iv) $F$ is continuous.

If there exist $x_{0}, y_{0} \in X$ such that $g\left(x_{0}\right) \leq F\left(x_{0}, y_{0}\right)$ and $g\left(y_{0}\right) \geq F\left(y_{0}, x_{0}\right)$, then $F$ and $g$ have a coupled coincidence point, that is, there exist $x, y \in X$ such that

$$
F(x, y)=g(x) \quad \text { and } \quad F(y, x)=g(y) .
$$

Proof Let $x_{0}, y_{0} \in X$ be such that

$$
\begin{aligned}
& \alpha\left(g\left(x_{0}\right), g\left(y_{0}\right)\right),\left(F\left(x_{0}, y_{0}\right), F\left(y_{0}, x_{0}\right)\right) \geq 1 \text { and } \\
& \alpha\left(g\left(y_{0}\right), g\left(x_{0}\right)\right),\left(F\left(y_{0}, x_{0}\right), F\left(x_{0}, y_{0}\right)\right) \geq 1
\end{aligned}
$$

and

$$
g\left(x_{0}\right) \leq F\left(x_{0}, y_{0}\right)=g\left(x_{1}\right) \quad \text { and } \quad g\left(y_{0}\right) \geq F\left(y_{0}, x_{0}\right)=g\left(y_{1}\right) .
$$

Let $x_{2}, y_{2} \in X$ be such that $F\left(x_{1}, y_{1}\right)=g\left(x_{2}\right)$ and $F\left(y_{1}, x_{1}\right)=g\left(y_{2}\right)$.

Continuing this process, we can construct two sequences $\left\{x_{n}\right\}$ and $\left\{y_{n}\right\}$ in $X$ as follows:

$$
g\left(x_{n+1}\right)=F\left(x_{n}, y_{n}\right) \quad \text { and } \quad g\left(y_{n+1}\right)=F\left(y_{n}, x_{n}\right) \quad \text { for all } n \geq 0 \text {. }
$$

Now we will show that

$$
g\left(x_{n}\right) \leq g\left(x_{n+1}\right) \quad \text { and } \quad g\left(y_{n}\right) \geq g\left(y_{n+1}\right) \quad \text { for all } n \geq 0 .
$$

For $n=0$, since $g\left(x_{0}\right) \leq F\left(x_{0}, y_{0}\right)$ and $g\left(y_{0}\right) \geq F\left(y_{0}, x_{0}\right)$ and as $g\left(x_{1}\right)=F\left(x_{0}, y_{0}\right)$ and $g\left(y_{1}\right)=$ $F\left(y_{0}, x_{0}\right)$, we have

$$
g\left(x_{0}\right) \leq g\left(x_{1}\right) \text { and } \quad g\left(y_{0}\right) \geq g\left(y_{1}\right) .
$$

Thus (3.2) holds for $n=0$. Now suppose that (3.2) holds for some fixed $n \geq 0$. 
Then since $g\left(x_{n}\right) \leq g\left(x_{n+1}\right)$ and $g\left(y_{n}\right) \geq g\left(y_{n+1}\right)$, therefore, by the $g$-mixed monotone property of $F$, we have

$$
\begin{aligned}
& g\left(x_{n+2}\right)=F\left(x_{n+1}, y_{n+1}\right) \geq F\left(x_{n}, y_{n+1}\right) \geq F\left(x_{n}, y_{n}\right)=g\left(x_{n+1}\right) \quad \text { and } \\
& g\left(y_{n+2}\right)=F\left(y_{n+1}, x_{n+1}\right) \leq F\left(y_{n}, x_{n+1}\right) \leq F\left(y_{n}, x_{n}\right)=g\left(y_{n+1}\right) .
\end{aligned}
$$

From above, we conclude that

$$
g\left(x_{n+1}\right) \leq g\left(x_{n+2}\right) \quad \text { and } \quad g\left(y_{n+1}\right) \geq g\left(y_{n+2}\right) .
$$

Thus, by mathematical induction, we conclude that (3.2) holds for all $n \geq 0$.

If the following holds for some $n$

$$
\left(g\left(x_{n+1}\right), g\left(y_{n+1}\right)\right)=\left(g\left(x_{n}\right), g\left(y_{n}\right)\right) \text {, }
$$

then, obviously, $F\left(x_{n}, y_{n}\right)=g\left(x_{n}\right)$ and $F\left(y_{n}, x_{n}\right)=g\left(y_{n}\right)$, i.e., $F$ has a coupled coincidence point.

Now, we assume that $\left(x_{n+1}, y_{n+1}\right) \neq\left(x_{n}, y_{n}\right)$ for all $n \geq n(\varepsilon)$.

Since $F$ and $g$ are $\alpha$-admissible, we have that

$$
\begin{aligned}
& \alpha\left(\left(g\left(x_{0}\right), g\left(y_{0}\right)\right),\left(g\left(x_{1}\right), g\left(y_{1}\right)\right)\right)=\alpha\left(\left(g\left(x_{0}\right), g\left(y_{0}\right)\right),\left(F\left(x_{0}, y_{0}\right), F\left(y_{0}, x_{0}\right)\right)\right) \geq 1 \quad \text { implies } \\
& \alpha\left(\left(F\left(x_{0}, y_{0}\right), F\left(y_{0}, x_{0}\right)\right),\left(F\left(x_{1}, y_{1}\right), F\left(y_{1}, x_{1}\right)\right)\right)=\alpha\left(\left(g\left(x_{1}\right), g\left(y_{1}\right)\right),\left(g\left(x_{2}\right), g\left(y_{2}\right)\right)\right) \geq 1 .
\end{aligned}
$$

Thus, by mathematical induction, we have

$$
\alpha\left(\left(g\left(x_{n}\right), g\left(y_{n}\right)\right),\left(g\left(x_{n+1}\right), g\left(y_{n+1}\right)\right)\right) \geq 1 .
$$

Similarly,

$$
\alpha\left(\left(g\left(y_{n}\right), g\left(x_{n}\right)\right),\left(g\left(y_{n+1}\right), g\left(x_{n+1}\right)\right)\right) \geq 1 \quad \text { for } n \in N \text {. }
$$

From (3.1) and conditions (i) and (ii) of the hypothesis, we get

$$
\begin{aligned}
d\left(g\left(x_{n}\right), g\left(x_{n+1}\right)\right) & =d\left(F\left(x_{n-1}, y_{n-1}\right), F\left(x_{n}, y_{n}\right)\right) \\
& \leq \alpha\left(\left(g\left(x_{n-1}\right), g\left(y_{n-1}\right)\right),\left(g\left(x_{n}\right), g\left(y_{n}\right)\right)\right) d\left(F\left(x_{n-1}, y_{n-1}\right), F\left(x_{n}, y_{n}\right)\right) \\
& \leq \psi\left(\frac{d\left(g\left(x_{n-1}\right), g\left(x_{n}\right)\right)+d\left(g\left(y_{n-1}\right), g\left(y_{n}\right)\right)}{2}\right) .
\end{aligned}
$$

Similarly, we have

$$
\begin{aligned}
d\left(g\left(y_{n}\right), g\left(y_{n+1}\right)\right) & =d\left(F\left(y_{n-1}, x_{n-1}\right), F\left(y_{n}, x_{n}\right)\right) \\
& \leq \alpha\left(\left(g\left(y_{n-1}\right), g\left(x_{n-1}\right)\right),\left(g\left(y_{n}\right), g\left(x_{n}\right)\right)\right) d\left(F\left(y_{n-1}, x_{n-1}\right), F\left(y_{n}, x_{n}\right)\right) \\
& \leq \psi\left(\frac{d\left(g\left(y_{n-1}\right), g\left(y_{n}\right)\right)+d\left(g\left(x_{n-1}\right), g\left(x_{n}\right)\right)}{2}\right) .
\end{aligned}
$$


Adding (3.5) and (3.6), we get

$$
\frac{d\left(g\left(x_{n}\right), g\left(x_{n+1}\right)\right)+d\left(g\left(y_{n}\right), g\left(y_{n+1}\right)\right)}{2} \leq \psi\left(\frac{d\left(g\left(x_{n-1}\right) g\left(x_{n}\right)\right)+d\left(g\left(y_{n-1}\right), g\left(y_{n}\right)\right)}{2}\right) .
$$

Repeating the above process, we get

$$
\frac{d\left(g\left(x_{n}\right), g\left(x_{n+1}\right)\right)+d\left(g\left(y_{n}\right), g\left(y_{n+1}\right)\right)}{2} \leq \psi^{n}\left(\frac{d\left(g\left(x_{0}\right) g\left(x_{1}\right)\right)+d\left(g\left(y_{0}\right), g\left(y_{1}\right)\right)}{2}\right), \quad n \in N \text {. }
$$

For $\varepsilon>0$, there exists $n(\varepsilon) \in N$ such that

$$
\sum_{n \geq n(\in)} \psi^{n}\left(\frac{d\left(g\left(x_{0}\right), g\left(x_{1}\right)\right)+d\left(g\left(y_{0}\right), g\left(y_{1}\right)\right)}{2}\right)<\frac{\varepsilon}{2}
$$

Let $n, m \in N$ be such that $m>n>n(\varepsilon)$, then by using the triangle inequality, we have

$$
\begin{aligned}
\frac{d\left(g\left(x_{n}\right), g\left(x_{m}\right)\right)+d\left(g\left(y_{n}\right), g\left(y_{m}\right)\right)}{2} & \leq \sum_{k=n}^{m-1} \frac{d\left(g\left(x_{k}\right), g\left(x_{k+1}\right)\right)+d\left(g\left(y_{n}\right), g\left(y_{n+1}\right)\right)}{2} \\
& \leq \sum_{n \geq n(\epsilon)} \psi^{n}\left(\frac{d\left(g\left(x_{0}\right), g\left(x_{1}\right)\right)+d\left(g\left(y_{0}\right), g\left(y_{1}\right)\right)}{2}\right) \\
& <\frac{\varepsilon}{2}, \\
d\left(g\left(x_{n}\right), g\left(x_{m}\right)\right)+d\left(g\left(y_{n}\right), g\left(y_{m}\right)\right) & <\varepsilon .
\end{aligned}
$$

Since

$$
\begin{aligned}
& d\left(g\left(x_{n}\right), g\left(x_{m}\right)\right) \leq d\left(g\left(x_{n}\right), g\left(x_{m}\right)\right)+d\left(g\left(y_{n}\right), g\left(y_{m}\right)\right)<\varepsilon \quad \text { and } \\
& d\left(g\left(y_{n}\right), g\left(y_{m}\right)\right) \leq d\left(g\left(x_{n}\right), g\left(x_{m}\right)\right)+d\left(g\left(y_{n}\right), g\left(y_{m}\right)\right)<\varepsilon,
\end{aligned}
$$

hence $g\left(x_{n}\right)$ and $g\left(y_{n}\right)$ are Cauchy sequences in $(X, d)$.

Since $(X, d)$ is complete, therefore, $g\left(x_{n}\right)$ and $g\left(y_{n}\right)$ are convergent in $(X, d)$.

There exist $x, y \in X$ such that $\lim _{n \rightarrow \infty} g\left(x_{n}\right)=x$ and $\lim _{n \rightarrow \infty} g\left(y_{n}\right)=y$.

By the continuity of $g$, we have

$$
\lim _{n \rightarrow \infty} g\left(g\left(x_{n}\right)\right)=g(x) \text { and } \lim _{n \rightarrow \infty} g\left(g\left(y_{n}\right)\right)=g(y) .
$$

By commutativity of $F$ and $g$, we get

$$
\begin{aligned}
& g\left(g\left(x_{n+1}\right)\right)=g\left(F\left(x_{n}, y_{n}\right)\right)=F\left(g\left(x_{n}\right), g\left(y_{n}\right)\right), \\
& g\left(g\left(y_{n+1}\right)\right)=g\left(F\left(y_{n}, x_{n}\right)\right)=F\left(g\left(y_{n}\right), g\left(x_{n}\right)\right) .
\end{aligned}
$$

We now show that

$$
\begin{aligned}
g(x) & =F\left(\lim _{n \rightarrow \infty} g\left(x_{n}\right), \lim _{n \rightarrow \infty} g\left(y_{n}\right)\right) \\
& =F(x, y),
\end{aligned}
$$




$$
\begin{aligned}
g(y) & =\lim _{n \rightarrow \infty} g\left(g\left(y_{n+1}\right)=\lim _{n \rightarrow \infty} F\left(g\left(y_{n}\right), g\left(x_{n}\right)\right)\right. \\
& =F(x, y) \quad \text { and } \quad g(y)=F(y, x) .
\end{aligned}
$$

Proceeding with limit $n \rightarrow \infty$ and using the continuity of $F$ in (3.7) and (3.8), we get

$$
\begin{aligned}
g(x) & =\lim _{n \rightarrow \infty} g\left(g\left(x_{n+1}\right)\right)=\lim _{n \rightarrow \infty} F\left(g\left(x_{n}\right), g\left(y_{n}\right)\right) \\
& =F\left(\lim _{n \leftarrow \infty} g\left(y_{n}\right), \lim _{n \rightarrow \infty} g\left(x_{n}\right)\right) \\
& =F(y, x) .
\end{aligned}
$$

Thus,

$$
g(x)=F(x, y) \quad \text { and } \quad g(y)=F(y, x) .
$$

Hence, we have proved that $F$ and $g$ have a coupled coincidence point.

Now, we will replace the continuity of $F$ in Theorem 3.2 by a condition on sequences.

Theorem 3.3 Let $(X, \leq)$ be a partially ordered set, and let there exist a metric $d$ on $X$ such that $(X, d)$ is a complete metric space. Let $F: X \times X \rightarrow X$ and $g: X \rightarrow X$ be maps, and let $F$ have the g-mixed monotone property. Suppose that there exist $\psi \in \Psi$ and $\alpha: X^{2} \times X^{2} \rightarrow$ $[0,+\infty)$ such that for $x, y, u, v \in X$ and the following:

(i) conditions (i), (ii) and (iii) of Theorem 3.2 and (3.1),

(ii) if $\left\{x_{n}\right\}$ and $\left\{y_{n}\right\}$ are sequences in $X$ such that

$$
\begin{aligned}
& \alpha\left(\left(g\left(x_{n}\right), g\left(y_{n}\right)\right),\left(g\left(x_{n+1}\right), g\left(y_{n+1}\right)\right)\right) \geq 1 \quad \text { and } \\
& \alpha\left(\left(g\left(y_{n}\right), g\left(x_{n}\right)\right),\left(g\left(y_{n+1}\right), g\left(x_{n+1}\right)\right)\right) \geq 1 \quad \text { for all } n
\end{aligned}
$$

and

$$
\lim _{n \rightarrow \infty} g\left(x_{n}\right)=x \text { and } \lim _{n \rightarrow \infty} g\left(y_{n}\right)=y \quad \text { for all } x, y \in X,
$$

then

$$
\alpha\left(\left(g\left(x_{n}\right), g\left(y_{n}\right)\right),(g(x), g(y))\right) \geq 1 \quad \text { and } \quad \alpha\left(\left(g\left(y_{n}\right), g\left(x_{n}\right)\right),(g(y), g(x))\right) \geq 1 \text {. }
$$

If there exist $x_{0}, y_{0} \in X$ such that $g\left(x_{0}\right) \leq F\left(x_{0}, y_{0}\right)$ and $g\left(y_{0}\right) \geq F\left(y_{0}, x_{0}\right)$, then $F$ and $g$ have a coupled coincidence point, that is, there exist $x, y \in X$ such that

$$
F(x, y)=g(x) \quad \text { and } \quad F(y, x)=g(y) .
$$

Proof Proceeding along the same lines as in the proof of Theorem 3.2, we know that $\left\{g\left(x_{n}\right)\right\}$ and $\left\{g\left(y_{n}\right)\right\}$ are Cauchy sequences in the complete metric space $(X, d)$. Then there exist $x, y \in X$ such that $\lim _{n \rightarrow \infty} g\left(x_{n}\right)=x$ and $\lim _{n \rightarrow \infty} g\left(y_{n}\right)=y$. 
On the other hand, from the hypothesis, we obtain

$$
\alpha\left(\left(g\left(x_{n}\right), g\left(y_{n}\right)\right),(g(x), g(y))\right) \geq 1,
$$

and similarly,

$$
\alpha\left(\left(g\left(y_{n}\right), g\left(x_{n}\right)\right),(g(y), g(x))\right) \geq 1 \text {. }
$$

Using the triangle inequality, (3.9) and the property of $\psi(t)<t$ for all $t>0$, we get

$$
\begin{aligned}
d(F(x, y), g(x)) & \leq d\left(F(x, y), F\left(x_{n}, y_{n}\right)\right)+d\left(g\left(x_{n+1}\right), g(x)\right) \\
& \leq \alpha\left(\left(g\left(x_{n}\right), g\left(y_{n}\right)\right),(g(x), g(y))\right) d\left(F\left(x_{n}, y_{n}\right), F(x, y)\right)+d\left(g\left(x_{n+1}\right), g(x)\right) \\
& \leq \psi\left(\frac{d\left(g\left(x_{n}\right), g(x)\right)+d\left(g\left(y_{n}\right), g(y)\right)}{2}\right)+d\left(g\left(x_{n+1}\right), g(x)\right) \\
& <\frac{d\left(g\left(x_{n}\right), g(x)\right)+d\left(g\left(y_{n}\right), g(y)\right)}{2}+d\left(g\left(x_{n+1}\right), g(x)\right) .
\end{aligned}
$$

Similarly, using (3.10), we have

$$
\begin{aligned}
d(F(y, x), g(y)) & \leq d\left(F(y, x), F\left(y_{n}, x_{n}\right)\right)+d\left(g\left(y_{n+1}\right), g(y)\right) \\
& \leq \alpha\left(\left(g\left(y_{n}\right), g\left(x_{n}\right)\right),(g(y), g(x))\right) d\left(F\left(y_{n}, x_{n}\right), F(y, x)\right)+d\left(g\left(y_{n+1}\right), g(y)\right) \\
& \leq \psi\left(\frac{d\left(g\left(y_{n}\right), g(y)\right)+d\left(g\left(x_{n}\right), g(x)\right)}{2}\right)+d\left(g\left(y_{n+1}\right), g(y)\right) \\
& <\frac{d\left(g\left(y_{n}\right), g(y)\right)+d\left(g\left(x_{n}\right), g(x)\right)}{2}+d\left(g\left(y_{n+1}\right), g(y)\right) .
\end{aligned}
$$

Proceeding with limit $n \rightarrow \infty$ in above two inequalities, we get

$$
d(F(x, y), g(x))=0 \quad \text { and } \quad d(F(y, x), g(y))=0 .
$$

Thus, $F(x, y)=g(x)$ and $F(y, x)=g(y)$.

Example 3.4 Let $X=[0,1]$ and $d: X \times X \rightarrow R$ be a standard metric.

Define a mapping $F: X \times X \rightarrow X$ by $F(x, y)=\frac{1}{4}(x-y)$ and $g: X \rightarrow X$ by $g(x)=\frac{x}{2}$ for all $x, y \in X$.

Consider a mapping $\alpha: X^{2} \times X^{2} \rightarrow[0,+\infty)$ to be such that

$$
\begin{aligned}
& \alpha((g(x), g(y)),(g(u), g(v)))= \begin{cases}1 & \text { if } g(x) \geq g(y) \text { and } g(u) \geq g(v), \\
0 & \text { otherwise, }\end{cases} \\
& d(F(x, y), F(u, v))=\left|\frac{(x-y)}{4}-\frac{(u-v)}{4}\right| \leq \frac{1}{4}(|x-u|+|v-y|)=\frac{1}{4}(d(x, u)+d(y, v)) .
\end{aligned}
$$


It follows that

$$
\begin{aligned}
& \alpha((g(x), g(y)), g((u), g(v))) d(F(x, y), F(u, v)) \\
& \quad \leq \frac{1}{4}(d(x, u)+d(y, v)) \leq \frac{1}{2}(d(x, u)+d(y, v)) \\
& \quad=(d(g(x), g(u))+d(g(y), g(v))) .
\end{aligned}
$$

Thus (3.1) holds for $\psi(t)=t$ for all $t>0$, and we also see that $F$ satisfies the $g$-mixed monotone property as well as $F$ and $g$ commute. Therefore, all the hypotheses of Theorem 3.2 are fulfilled. Then there exists a coupled coincidence point of $F$ and $g$. In this case, $(0,0)$ is a coupled coincidence point of $F$ and $g$.

\section{Competing interests}

The authors declare that they have no competing interests.

\section{Authors' contributions}

All authors contributed equally and significantly in writing this article. All authors read and approved the final manuscript.

\section{Author details}

'Department of Mathematics, DCRUST, Murthal, Sonepat 131039, India. ${ }^{2}$ Department of Mathematics, Faculty of Science, King Mongkut's University of Technology, Thonburi (KMUTT), Bang Mod, Thrung Khru, Bangkok, 10140, Thailand.

\section{Acknowledgements}

One of the authors (Sanjay Kumar) is thankful to UGC for providing Major Research Project F.No. 39-41/2010(SR). Also, the authors thank the editors and referees for their insightful comments. Moreover, the third author would like to thank the Higher Education Research Promotion and National Research University Project of Thailand, Office of the Higher Education Commission for financial support under grant No. NRU56000508.

\section{Received: 19 March 2013 Accepted: 22 October 2013 Published: 28 Nov 2013}

\section{References}

1. Bhaskar, TG, Lakshmikantham, V: Fixed point theorems in partially ordered metric spaces and applications. Nonlinear Anal. 65, 1379-1393 (2006)

2. Lakshmikantham, V, Ćirić, LB: Coupled fixed point theorems for nonlinear contractions in partially ordered metric spaces. Nonlinear Anal. 70, 4341-4349 (2009)

3. Choudhury, BS, Kundu, A: A coupled coincidence point result in partially ordered metric spaces for compatible mappings. Nonlinear Anal. 73, 2524-2531 (2010)

4. Luong, NV, Thuan, NX: Coupled fixed points in partially ordered metric spaces and application. Nonlinear Anal. 74 983-992 (2011)

5. Nieto, JJ, Rodríguez-López, R: Contractive mapping theorems in partially ordered sets and applications to ordinary differential equations. Order 22, 223-239 (2005)

6. Nieto, JJ, Rodriguez-López, R: Existence and uniqueness of fixed point in partially ordered sets and applications to ordinary differential equations. Acta Math. Sin. Engl. Ser. 23(12), 2205-2212 (2007)

7. Ran, ACM, Reurings, MCB: A fixed point theorem in partially ordered sets and some applications to matrix equations. Proc. Am. Math. Soc. 132, 1435-1443 (2004)

8. Samet, B: Coupled fixed point theorems for a generalized Meir-Keeler contraction in partially ordered metric spaces. Nonlinear Anal. 72, 4508-4517 (2010)

9. Nashine, HK, Kadelburg, Z, Radenović, S: Coupled common fixed point theorems for $w$-compatible mappings in ordered cone metric spaces. Appl. Math. Comput. 218, 5422-5432 (2012)

10. Agarwal, RP, El-Gebeily, MA, O’Regan, D: Generalized contractions in partially ordered metric spaces. Appl. Anal. 87, 109-116 (2008)

11. Ćirić, L, Cakić, N, Rajović, M, Ume, JS: Monotone generalized nonlinear contractions in partially ordered metric spaces. Fixed Point Theory Appl. 2008, Article ID 131294 (2008)

12. Karapinar, E, Samet, B: Generalized $\alpha-\psi$-contractive type mappings and related fixed point theorems with applications. Abstr. Appl. Anal. 2012, Article ID 793486 (2012)

13. Aydi, H, Samet, B, Vetro, C: Coupled fixed point results in cone metric spaces for $W$-compatible mappings. Fixed Point Theory Appl. 2011, Article ID 27 (2011)

14. Jleli, M, Cojbasic Rajic, V, Samet, B, Vetro, C: Fixed point theorems on ordered metric spaces and applications to nonlinear elastic beam equations. J. Fixed Point Theory Appl. (2012). doi:10.1007/s11784-012-0081-4

15. Samet, B, Vetro, C, Vetro, P: Fixed point theorems for $\alpha$ - $\psi$-contractive type mappings. Nonlinear Anal. 75, 2154-2165 (2012)

16. Nashine, HK, Samet, B, Vetro, C: Coupled coincidence points for compatible mappings satisfying mixed monotone property. J. Nonlinear Sci. Appl. 5(2), 104-114 (2012) 
17. Samet, B, Vetro, C: Coupled fixed point, F-invariant set and fixed point of $n$ order. Ann. Funct. Anal. 1(2), 46-56 (2010)

18. Samet, B, Vetro, C: Coupled fixed point theorems for multi-valued nonlinear contraction mappings in partially ordered metric spaces. Nonlinear Anal. 74, 4260-4268 (2011)

19. Mursaleen, M, Mohiuddine, SA, Agarwal, RP: Coupled fixed point theorems for $\alpha$ - $\psi$-contractive type mappings in partially ordered metric spaces. Fixed Point Theory Appl. (2012). doi:10.1186/1687-1812-2012-228

10.1186/1687-1812-2013-325

Cite this article as: Kaushik et al.: Coupled coincidence point theorems for $\alpha$ - $\psi$-contractive type mappings in partially ordered metric spaces. Fixed Point Theory and Applications 2013, 2013:325

Submit your manuscript to a SpringerOpen ${ }^{\circ}$ journal and benefit from:

- Convenient online submission

- Rigorous peer review

Immediate publication on acceptance

Open access: articles freely available online

- High visibility within the field

- Retaining the copyright to your article 